\title{
Thank you to our Reviewers
}

We are indebted to the expert referees who have reviewed submissions to The Canadian Journal of Neurological Sciences in 2015. Their thoughtfulness and expertise have served our journal well.

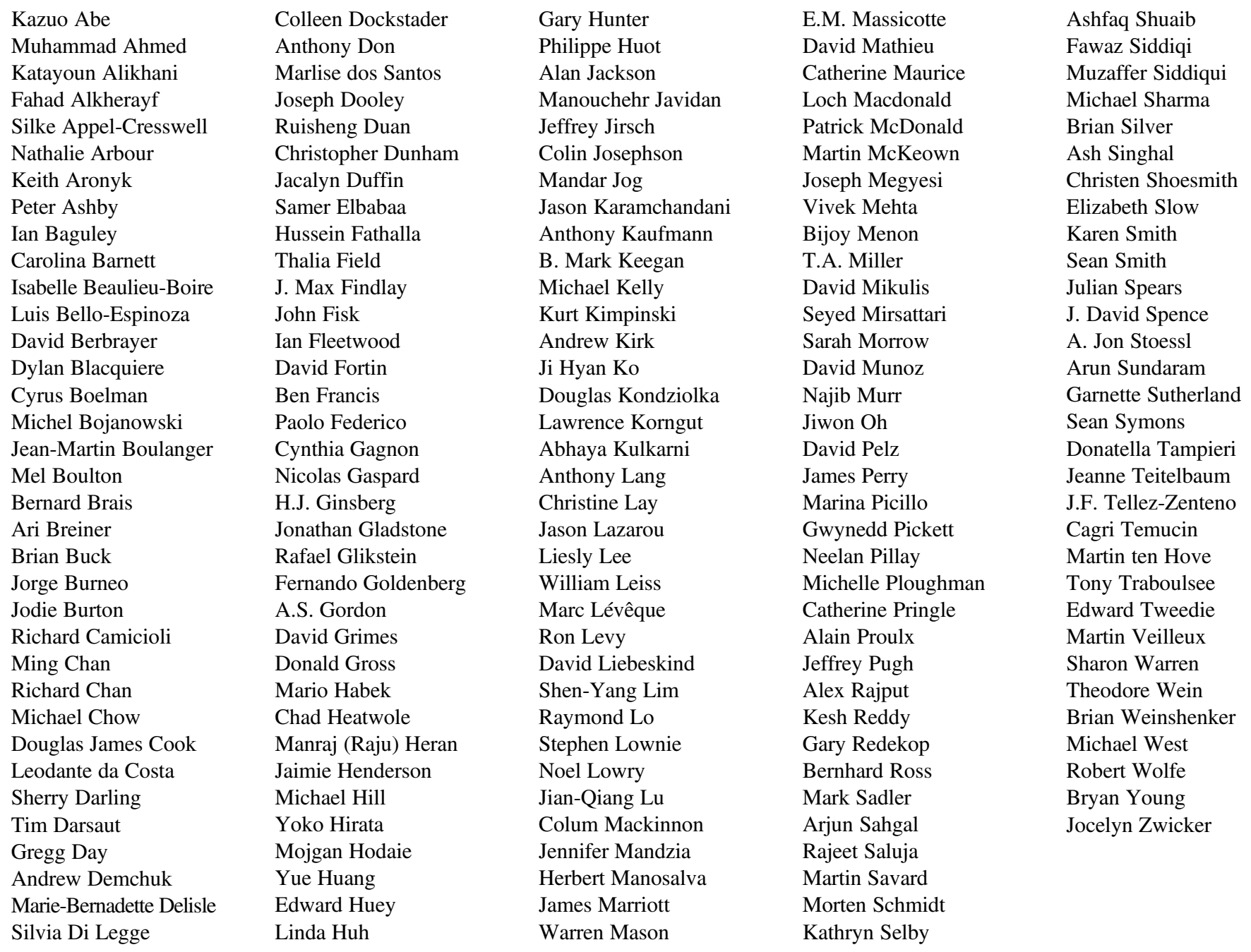

